\title{
Editorial
}

\section{Contra el optimismo historicista de la transición}

Usualmente escuchamos en palabras de ciertos politicos salvadorehos, de algunos analistas de ls vida nacional y de muchos ciudadanos -pues ya es del dominio público- que el pals se encuentra en un "proceso de transición" a la democracia; que nos encontramos inmersos en un proceso dinámico e histórico que apunta hacia la vida democrática. Pero, deteniéndonos un poco en estas frases nos viene una interrogante a nuestra mente que no resulta ocioso intentar darle una respuesta: len realidad nos hallamos inexorablemente situados dentro de una logica historica que nos llevart tarde o temprano a una futura vida de planificación democrática? ¿Son las fuerzas de una lógica histórica, de un destino desconocido o de un dinamismo natural las que nos mueven a esa meta? $Y$, en todo caso, la qué vida democrática vamos transitando de acuerdo con dichas leyes? Con respecto a las dos primeras interrogantes creemos que no hay tales leyes que nos muevan. Como seres humanos somos libres $\rightarrow$ sin olvidar que estamos condicionados por múltiples variables - para optar por la forma de vida privada o nacional que deseamos. Con respecto a la segunda interrogante, debemos ser precavidos en no aceptar como deseable "cualquier" tipo de democracia.

La democracia, tomada en su forma más englobante y más deseada, es decir, como estilo de vida, no so encuentra la vuelta de nuestra casa. Es necesario construirk, fijar sus cimientos. Pero si nosotros deseamos otro modo de vida social no habra detras de nuestras decisiones una fuerza oculta que lo impida. Con lo cual no estamos queriendo decir que no deseamos o aspiramos construir de distintas maneras una sociedad cada vez más participativa y respetuosa de los 
derechos humanos. No. Simplemente, que la dirección de nuestras aspiraciones no debe comprenderse en 1 terminos de una logica determinista - por muy bonancibles que sean sus resultados. Los condicionamientos a los que estamos "sometidos" como seres biopsicosociales no representan una fuerza oculta o extratia a nosotros mismos que nos mueve hacia destinos conocidos o desconocidos.

Despues de los acontecimientos de la cafda del socialismo real, muchos escritores liberales y neoliberales han resbalado en una consideración metaflsica que ellos mismos le refutaban a las ideologias marxistas: el optimismo historicista. Asl, Fukuyama ha embelesado a muchos sobre su "final de la historia". Por su parte, Giovanni Sartori ha declarado que "el viento de la historia ha cambiado de dirección y sopla en un único sentido: hacia la democracia. (...) Para el Zeitgeist, el eapiritu de nuestro tiempo, la democracia ya no tiene enemigo: ya no está amenazada por legitimidades alternativas"'. Pero, $i$ a cuál democracia se refiere Sartori? No hay duda que a la "democracia liberal": "la disolución del comunismo nos deja frente a un vencedor absoluto: la democracia liberal"n.

Este optimismo metafísico e histórico de muchos liberales los condena a caer en similar optimismo que en sus dras pregonaron muchos intelectuales y seguidores del manxismo. La critica al profetismo marxista de un futuro socialista y la creencia de que existen leyes dialtecticas que mueven los destinos de los hombres hacia ese futuro feliz, llevó a los liberales a ofrecer una alternativa que desliza tambien por el mismo corredor. No resulta atrevido pensar, entonces, que durante el siglo XX han sido algunas tendencias marxistas y liberales las que han mostrado a nivel político ese profetismo escatologico, esa herencia ilustrada del "progreso" hacia mejores mundos posibles.

El optimismo marxista de principios de siglo caló profundamente en el movimiento comunista salvadoreflo de los años treinta. $Y$, por qué no decirlo, dicha influencia continuó fortaleciéndose en los movimientos marxistas posteriores a los afios veinte y treinta. Conceptos como "la hora del socialismo ha llegado". "la inevitabilidad del socialismo"', entre otros, muestran cómo existla un universo ideológico que apuntaba a un supuesto "final de la historia" de carácter socialista en El Salvador. Muchos que esperaron con ansiedad al "mesias" sacrificaron sus vidas y bienes. Otros, los que lograron sobrevivir, experimentan o disfrutan la "anútesis" de su proceso dialéctico con la comodidad y la apatía que aquella ofrece.

Pero, el optimismo historicista que est́́ permeando fuertemente en estos momentos es el neoliberal. Sus leyes ocultas no son necesariamente dialécticas; sin embergo, viene jugando con las categorfas de "destrucción-superación" de su rival confeso. Su personalidad pretende mostrarse tal como lo hizo en su momento el marxismo- como cientffica y, por ende, incuestionable e irrefutable. La democracia, en el ámbito sociopolítico, es la defensa que el optimismo 
historicista neoliberal realiza actualmente. Pero, se trata de una democracia a medias, pues su imaginario se reduce a la representación popular y a la participación electoral. Esta es la "mela" histórica a la que tarde o temprano llegaremos. Se podrfa decir que este imaginario ya se ha realizado en la historia de nuestro pals y que, es más, ha tenido una prolongada legitimación a su favor. No obstante, la nueve meta histórica, el nuevo mesfas no será más que la democracia -como procedimiento político- que se verá completado con la planificación neoliberal en el campo económico. "¿Hacia dónde vamos?", se preguntarán, pues, -conociendo anticipadamente la respuesta- los intelectuales del neoliberalismo. La respuesta, como ya hemos visto, es: "transitamos de un estado de guerra de todos contra todos, de una vida autoritaria a la vida democrática".

La crítica a la teleología secular o "cientificista" tanto del marxismo como del neoliberalismo no pretende renegar a cualquier intento utopico que "oriente" los esfuerzos humanos por crear una sociedad cada vez más humanizante. Lo que ha sucedido es que la utopía, en cuanto un ideal buscado, se ha malentendido como una fuerza o "mano oculta" que opera independiente de las acciones humanas. ¿Desde dónde podemos, entonces, presentar los lineamientos para una alternativa a estos optimismos historicistas - sobre todo al que está apelando su vigencia en nuestro pafs y a nivel mundial? La clave la encontramos en el cơmo entenderemos la "historia humana". Es claro que los historicismos a los que hemos aludido tienen detrás una justificación metafísica de la historia A simple vista, nos damos cuenta que ambos participan de una idea ilustrada de la historia, es decir, una idea en la que los acontecimientos humanos van caminando hacia una meta feliz (progreso) y que dichos acontecimientos son susceptibles de ser comprendidos racionalmente (estatuto cientffico).

Si la concepción ilustrada de la historia es la que fundamenta al historicismo neoliberal - tal como lo hizo también con el marxista-, entonces nos alienta el hecho de la crisis actual de muchos paradigmas ilustrados a efecto de buscar otras posibilidades, pues esta crisis nos permite tener un motivo para argumentar que hay a disposición otros referentes teóricos para concebir una historia de la humanidad que rehuya a los determinismos. La historia no está ya hecha, pues no es una entidad que escapa a las voluntades humanas, ni mucho menos se trata de un "ser" que se impone a los individuos desde la exterioridad de aquéllos. La historia la hacen los individuos, por lo que hay una tension entre lo individual y lo colectivo en la configuración de ésta. Si el curso de los acontecimientos está sujeto a las decisiones de todos aquellos que participan (individuos e instituciones), entonces las decisiones no pueden ser predecibles o determinadas de antemano. Que los análisis marxistas cayeron en la profecla de adelantarse a las cosas fue uno de sus mayores errores. Si del esclavismo se transitó al feudalismo, de éste al capitalismo y del capitalismo se "esperara" una vida socialista, 
por contener cada etapa de la historia los germenes de su propia eliminación, ello no evidencia más que un anflisis decimonónico de ver los acontecimientos.

Quizá uno de los primeros aspectos que ha contribuido a desarticular una concepción de historia de corte determinista es la formulación insistente, durante estos últimos aflos, de una "antropologáa de la concreción": es decir, considerar a los seres humanos como seres histórico-concretos. Marx ya lo habla aportado, siguiendo a Feuerbach: los hombres son seres de "came y hueso", sostenía; pero todo parece que muchas tradiciones marxistas poco siguieron esta concepción, porque cuando al hombre se le ubicó en el papel de actor en la historia, éste quedó atado siempre a sus inevitables etapas. Si el ser humano, entonces, ya no es visto únicamente desde su esencia, y mucho menos de una esencia inmutable, todo parece que el camino para una interpretación distinta de el y de la historia ha quedado abierto. Su carácter de actor y autor de los procesos sociales e individuales quedan bajo nuevas posibilidades hermenéticas. Con lo cual, la historia ya no se nos aparece ni como un concepto - cuando se habla de ella no se debe pensar en términos idealistas - ni como una concreción providencialmente destinada a un fin. La historia humana será un proceso configurado por múltiples procesos humanos. Dichos procesos pueden concebirse como el encuentro entre el individuo con sus circunstancias (recordemos a Ortega y Gasset). Lo que al individuo le circunda, su mundo, su realidad, le impele a responder, a optar. La realidad, dirá Zubiri, le ofrece una variedad de posibilidades a los hombres para que éstos opten por unas, desechando o reinventando otras.

Si los sujetos son libres y capaces de elegir sus propias circunstancias, el individuo o los individuos se convierten en autores. Autores de sus vidas y de las vidas de los otros. Pero también los otros se convierten en autores del primero. Por ello, el discurso actual del neoliberalismo de supeditar el curso de nuestras vidas a una "lógica natural del mercado" es tan absurdo como pemicioso. Absurdo porque el mercado no representa ni a la población mundial ni a sus intereses. Pemicioso porque sus consecuencias son desastrosas para más de tres cuartos de la población mundial. Sin embargo, no es que se trate ahora de apelaciones a una muerte o destrucción del mercado: su "exterminio total"; ni mucho menos, vaticinar una nueva calda. De lo que se trata es de plantear soluciones que humanicen dicha realidad: jel mercado es una realidad con la cual tenemos que convivir! Sin embargo, su convivencia con nosolros deberd plantearse desde una perspectiva más humanizante y crítica. Habra que proponerle un "mínimo" de criterios que sustituyan a aquellos que han mostrado una ineficacia en el ámbito humano, social, político y ecológico. Y la tarea contemporánea de los planteamientos y debates sobre cómo se puede reconducir la lógica neoliberal es parte - muy pequeña por cierto- de una concepción de historia en claves más dinámicas y menos deterministas. Es cierto que el planteamiento de teorias y propuestas éticas de cómo deben ser las actuaciones del mercado no representan abrumadoramente las actuaciones de los individuos e 
instituciones en razón de construir una historia distinta. Sin embargo, el papel de la palabra, del discurso o del debate de ideas no dehe faltar. Hannah Arendt, en su preocupación por la lógica tocalitaria y masificadora de ciertos regímenes occidentales, concibió que el ser humano se caracteriza por el discurso y la acción'.

Si retomamos las ideas de Arendt, pero pasando por nuestra propia interpretación, podemos recalcar que la historia humana es resultado de las acciones individuales y grupales. Una acción determinada, un hecho, no tiene por qué ser un hecho definitivo, un resultado acabado. Los resultados acabados se dan, pero no se dan de una vez por todas. Mientras los individuos continúen, mientras la especie humana siga sobre la faz de la tierra, las innumerables respuestas a las posibilidades que las circunstancias les ofrezcan a ellos serán muy variadas. Y entre estas respuestas no sólo están los hechos individuales y colectivos, sino también cobrará vigencia el discurso. El problema con el optimismo neoliberal -y en su tiempo, el marxista- es que cree que sus acciones son definitivas, son las mejores ( ${ }_{\mathrm{i}} \mathrm{El}$ mejor de los mundos posibles!). Y por ser definitivas ni los individuos ni las colectividades pueden hacer nada más. La historia, pues, es una línea continua hacia su inevitable meta. Ya no digamos del discurso. El papel del discurso - y sobre todo del discurso que disiente-, queda dentro de este optimismo con un sabor a un reconocible totalitarismo. No hay espacio para el debate. Se dice que la democracia liberal permite la libre discusión de ideas. Pero este optimismo historicista se presenta como el único discurso capaz de no ser superado por otro, con lo cual se cancela subrepticiamente cualquier intento de replanteamientos.

Una historia, entonces, en constante apertura a modos de situarse en el mundo y en la que construir, reconstruir, renovar o crear las circunstancias dependa de los humanos (grupos sociales, instituciones, pueblos, etnias, etc.) nos parece más adecuada para enfrentarse al optimismo neoliberal de una transición hacia la democracia. La transición hacia un modo de vida democrático es deseable y deseado. Pero no vamos irremediablemente a él -al que nos quieren hacer creer que vamos. Tenemos la capacidad de elegir qué modelo de vida democrático queremos. Y es ahl donde no sólo la acción desempeña su papel, sino que se requiere del discurso. Volvemos hacernos la pregunta: ¿hacia dónde vamos? La respuesta, aunque suene a utopla renacentista, es que vamos hacia donde querramos elegir, a pesar de los tropiezos que el mundo circundante nos imponga.

\section{Notas}

I. Santori, G. La democracia después del comunismo. Madrid: Alianza editorial. 1994, pp. 25-26.

2. Ibid., p. 16.

3. González, L. A. "Las ideologlas pulíticas en América Latina en el siglo XX", en ECA, No. 585-586, 1997, pp. 682-683.

4. Arendt, H. De la historia a la acción. Barcelona: Paidós. 1995. pp. 103-107. 